Research article

\title{
Common ERBB2 polymorphisms and risk of breast cancer in a white British population: a case-control study
}

\author{
Patrick R Benusiglioㄹ, Fabienne Lesueur ${ }^{1}$, Craig Luccarini ${ }^{1}$, Donald M Conroy ${ }^{1}$, Mitul Shah ${ }^{1}$, \\ Douglas F Easton ${ }^{2}$, Nick E Day ${ }^{3}$, Alison M Dunning ${ }^{1}$, Paul D Pharoah ${ }^{1}$ and Bruce AJ Ponder ${ }^{1}$
}

\author{
1Department of Oncology, University of Cambridge, Strangeways Research Laboratories, Cambridge, UK \\ 2Department of Genetic Epidemiology, University of Cambridge, Strangeways Research Laboratories, Cambridge, UK \\ ${ }^{3} \mathrm{EPIC}$, University of Cambridge, Strangeways Research Laboratories, Cambridge, UK \\ Corresponding author: Patrick R Benusiglio, patrick@srl.cam.ac.uk \\ Received: 17 Aug 2004 Revisions requested: 15 Oct 2004 Revisions received: 29 Nov 2004 Accepted: 1 Dec 2004 Published: 12 Jan 2005 \\ Breast Cancer Res 2005, 7:R204-R209 (DOI 10.1186/bcr982) \\ (C) 2005 Benusiglio et al.; licensee BioMed Central Ltd. \\ This is an Open Access article distributed under the terms of the Creative Commons Attribution License (http://creativecommons.org/licenses/by/ \\ 2.0), which permits unrestricted use, distribution, and reproduction in any medium, provided the original work is cited.
}

\begin{abstract}
Introduction About two-thirds of the excess familial risk associated with breast cancer is still unaccounted for and may be explained by multiple weakly predisposing alleles. A gene thought to be involved in low-level predisposition to the disease is ERBB2 (HER2). This gene is involved in cell division, differentiation, and apoptosis and is frequently amplified in breast tumours. Its amplification correlates with poor prognosis. Moreover, the coding polymorphism I655V has previously been associated with an increased risk of breast cancer.
\end{abstract}

Methods We aimed to determine if common polymorphisms (frequency $\geq 5 \%$ ) in ERBB2 were associated with breast cancer risk in a white British population. Five single-nucleotide polymorphisms (SNPs) were selected for study: SNP 1 near the promoter, SNP 2 in intron 1, SNP 3 in intron 4, SNP 4 in exon 17 (I655V), and SNP 5 in exon 27 (A1170P). We tested their association with breast cancer in a large case-control study ( $n$ $=2192$ cases and 2257 controls).

Results There were no differences in genotype frequencies between cases and controls for any of the SNPs examined. To investigate the possibility that a common polymorphism not included in our study might be involved in breast cancer predisposition, we also constructed multilocus haplotypes. Our set of SNPs generated all existing $(n=6)$ common haplotypes and no differences were seen in haplotype frequencies between cases and controls $(P=0.44)$.

Conclusions In our population, common ERBB2 polymorphisms are not involved in predisposition to breast cancer.

Keywords: breast cancer, case-control study, ERBB2, haplotype, single-nucleotide polymorphism

\section{Introduction}

Breast cancer is the most common cause of cancer in women in the United Kingdom and is, after lung cancer, the most common cause of cancer death (Office for National Statistics). Positive family history is a well-established risk factor for the disease: the risk to first-degree relatives of a breast cancer case is about twice the population risk [1]. Most of the excess familial risk associated with breast cancer is likely to be genetic in origin $[2,3]$. However, only about a third of this risk is accounted for by known genes, the most important being BRCA1 and BRCA2, while the remainder might be explained by a combination of weakly predisposing alleles [2-4]. A gene thought to be involved in low-level susceptibility to breast cancer is ERBB2 (HER2).
This gene is located on chromosome 17q12-q21, spans 38 kilobases, and comprises 27 coding exons. It is a member of the ERBB family, a family of protein tyrosine kinases involved in cell division, migration, adhesion, differentiation, and apoptosis and consisting of EGFR (ERBB1), ERBB2, ERBB3, and ERBB4 [5]. ERBB2 amplification or overexpression is seen in about $25 \%$ of breast cancers and has been associated with metastatic phenotype, endocrine therapy unresponsiveness, and poor prognosis [6]. ERBB2 is polymorphic in the transmembrane region of the protein at codon 655 (ATC/isoleucine to GTC/valine [1655V]). The amino acid change could result in increased protein tyrosine kinase activity [7]. Several association studies of $1655 \mathrm{~V}$ and breast cancer risk have yielded conflicting 
results. In a study on 700 Han Chinese women, Xie and colleagues first reported a significantly increased risk for carriers of the rare allele (odds ratio $[O R]=1.4$ ) [8]. Only one of seven subsequent studies showed an overall effect of I655V on breast cancer risk [9-15]. However, of the negative studies, all but one had limited power to detect a risk of this magnitude [13]. Three groups did report associations in specific subgroup analyses in the absence of overall effect: Wang-Gohrke and Chang-Claude showed an association in women with a positive family history of breast cancer and McKean-Cowdin and colleagues showed an association with localized breast cancer, whereas Millikan and colleagues showed an association in women with a positive family history who were aged 45 years or younger as well as an increased risk of carcinoma in situ $[12,13,15]$.

$1655 \mathrm{~V}$ has usually been selected for study because of the possible functional consequences of the amino acid change in the transmembrane region of the protein. Many more single-nucleotide polymorphisms (SNPs) in ERBB2 are known but only one negative study has reported on any of these [10]. A selected set of sequence polymorphisms can serve as genetic markers to detect association between a particular region and the disease, whether or not the markers themselves have a functional effect [16]. It is therefore not necessary to test each polymorphism individually. Because most SNPs are correlated with nearby polymorphisms, genotypes at unsassayed, risk-related SNPs will be correlated with one or more assayed SNPs [17]. If the set of selected markers provides enough information about the remainder of the common polymorphisms in that gene, any susceptibility allele within or close to the gene should be uncovered through the evaluation of the underlying haplotypes [18]. To clarify the role of ERBB2 in the predisposition to breast cancer, we tested the association of five common polymorphisms (including 1655V) with the disease in a large case-control study of white British women. We aimed to identify sufficient SNPs to tag all the common haplotypes across the gene.

\section{Materials and methods Patients and controls}

Cases were drawn from the Anglian Breast Cancer Study, an ongoing population-based study with cases ascertained through the East Anglian Cancer Registry [4]. All women diagnosed with invasive breast cancer under the age of 55 years between 1 January 1991 and 30 June 1996 and who were alive at the start of the study (prevalent cases) as well as women under the age of 70 who were diagnosed from 1996 onwards (incident cases) were eligible for inclusion. We used prevalent and incident cases in order to maximize sample size; approximately $65 \%$ of eligible patients have enrolled in the study. Women taking part in the study were asked to provide a $20-\mathrm{ml}$ blood sample for DNA analysis and to complete a comprehensive epidemiological ques- tionnaire. We carried out genotyping on a subset consisting of the first 2192 (1438 incident and 754 prevalent) enrolled cases. Controls (2257) were randomly drawn from the Norfolk component of the European Prospective Investigation of Cancer (EPIC) [19]. The ethnic background of both cases and controls is similar, with over $98 \%$ being white Anglo-Saxon. Ethical approval was obtained from the Anglia and Oxford Multicentre Research Committee and informed consent was obtained from each patient.

\section{SNP identification and selection}

SNPs with validated frequency data were identified in January 2004 through the dbSNP database http:// www.ncbi.nlm.nih.gov/SNPI. If these data were from a nonCaucasian population, we confirmed the presence of the polymorphism in our population by performing denaturing high-performance liquid chromatography on a set of 48 genomic DNA samples from UK breast cancer patients. We selected all nonsynonymous coding SNPs $(n=2)$, SNPs located in the promoter region $(n=1)$, and two randomly chosen intronic SNPs [20]. A total of five SNPs were thus selected for study (Table 1). In order to have good power to detect small relative risks, we restricted our attention to SNPs with a frequency of $5 \%$ or more.

\section{Genotyping}

Genotyping was carried out using Taqman ${ }^{\circledR}$ (Applied Biosystems, Warrington, UK) according to the manufacturer's instructions. Primers and probes were either supplied directly by Applied Biosystems in case of Assays-byDesign $^{\mathrm{TM}}$ (SNP 1 and SNP 2) and Assays-on-Demand ${ }^{\mathrm{TM}}$ (SNP 3) or designed using Primer Express Oligo Design Software v2.0 (Applied Biosystems) (SNP 4 and SNP 5). Sequences are available on request. Reactions were carried out at $54^{\circ} \mathrm{C}$ (SNP 4) or $60^{\circ} \mathrm{C}$ (SNP 1, SNP 2, SNP 3, and SNP 5). All assays were carried out in 384-well plates. Each plate contained 384 samples including 2 negative controls with no DNA and 12 samples duplicated on a separate quality-control plate. Plates were read on the $A B I$ Prism 7900 using the Sequence Detection Software (Applied Biosystems). Failed genotypes were not repeated.

\section{Statistical methods}

The characteristics of cases and controls were explored with SPSS ${ }^{\odot}$ v12.0.1 (SPSS Inc, Chicago, IL, USA). For each SNP, deviation of genotype frequencies in controls from the Hardy-Weinberg equilibrium was assessed by $\chi^{2}$ test with one degree of freedom (df). Genotype frequencies in cases and controls or within cases stratified by disease stage (stage I vs stages II-IV) or age group ( $\leq 45$ vs $>45$ ) were compared by $\chi^{2}$ test for heterogeneity ( $2 \mathrm{df}$ ). Genotype-specific risks were estimated as ORs using standard cross-product ratio. Confidence intervals were calculated using the variance of the log (OR), which was estimated by the standard Taylor expansion. Power was 
Table 1

\begin{tabular}{|c|c|c|c|}
\hline SNP name & $\mathrm{dbSNP}$ id & Location & Base change \\
\hline SNP 1 & rs4252596 & START $-657^{a}$ & $C>A^{b}$ \\
\hline SNP 2 & rs2952155 & intron 1 & $\mathrm{C}>\mathrm{T}$ \\
\hline SNP 3 & rs1810132 & intron 4 & $\mathrm{D}>\mathrm{C}$ \\
\hline SNP 4 & rs 1801200 & exon 17 (1655V) & $A>G$ \\
\hline SNP 5 & rs1058808 & exon 27 (A1170P) & $\mathrm{G}>\mathrm{C}$ \\
\hline
\end{tabular}

a 657 base pairs upstream first translated base. ${ }^{b}$ Common allele given first.

determined using standard statistical methods [21]. We have over $90 \%$ power at the $1 \%$ significance level to detect a dominant allele with a frequency of 0.05 , which confers a relative risk of 1.5 , or a dominant allele with a frequency of 0.2 that confers a relative risk of 1.3. Power to detect recessive alleles at the $1 \%$ significance level is more limited: $59 \%$ for an allele with a frequency of 0.2 that confers a relative risk of 1.5 or $77 \%$ for an allele with a frequency of 0.3 that confers a relative risk of 1.4. The LDA program [22] was used to calculate pairwise linkage disequilibrium (LD) for each SNP pair in the whole case-control set. The haplo.score program [23] was used to test for association between haplotypes and breast cancer risk. Haplo.score uses a likelihood that depends on estimated haplotype frequencies to test the statistical association between haplotypes and phenotype. It is based on score statistics, which provide both global tests and haplotype-specific tests [23].

\section{Results}

The median age was 48 years (range 25-54) for prevalent cases, 52 years (26-55) for incident cases, and 56 years (25-81) for controls. Incident and prevalent cases were similar regarding breast cancer stage $(P=0.12)$ and histological grade $(P=0.41)$. Table 2 shows the genotype frequencies in cases and controls as well as genotypespecific risks for the five SNPs assayed. The genotype frequencies were similar in the prevalent and incident cases for all polymorphisms (data not shown). None of the genotype distributions for the controls differed significantly from those expected under Hardy-Weinberg equilibrium. There was no evidence that any of the SNPs is associated with breast cancer; genotype-specific ORs were all close to unity with narrow confidence intervals. We also compared genotype frequencies within cases stratified by disease stage and age group for SNP $4(1655 \mathrm{~V})$. No differences were seen $(P$ [stage] $=0.61, P$ [age group] $=0.33)$. LD was strong $\left(D^{\prime}>0.7\right)$ across pairs involving SNPs 1, 2, 3, and 5 , whereas SNP 4 was in weak LD $\left(D^{\prime}<0.3\right)$ with all other polymorphisms except SNP 1 (D' [SNP 1-SNP 4] = $0.98)$ (Fig. 1). SNPs 3 and 5 were in nearly perfect LD $\left(r^{2}\right.$ $=0.92$ ). Of 32 possible haplotypes, only 6 were observed with a frequency greater than $5 \%$ (Table 3). For the whole
Figure 1

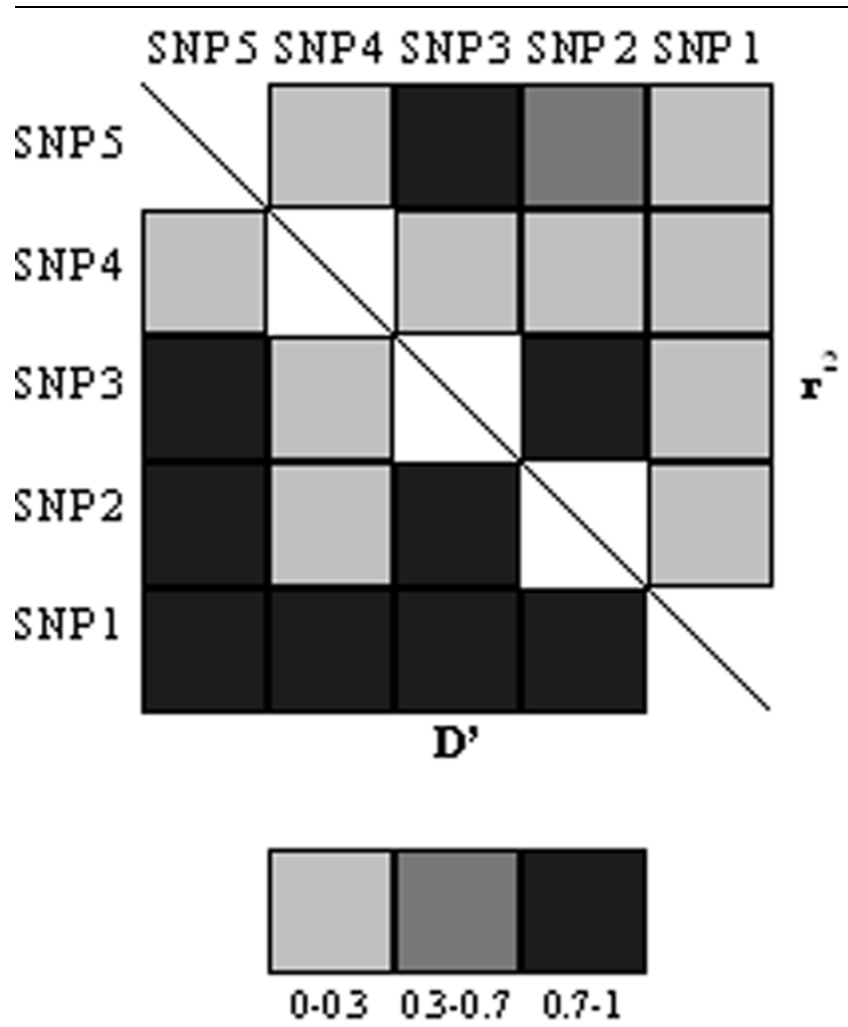

Pairwise linkage disequilibrium (LD) measures of D' (left bottom half) and $r^{2}$ (right top half) for the five SNPs.

case-control set, common haplotypes constituted $98 \%$ of all the observed haplotypes. Two haplotypes (haplotypes 3 and 5) contained the SNP 4 (I655V) minor allele. The global test was not significant $(P=0.44)$, nor were there any differences between cases and controls for individual haplotypes. Similarly, no differences in haplotype frequencies were seen within cases stratified by disease stage $(P=$ $0.37)$ or age group $(P=0.48)$.

\section{Discussion}

Our study is the largest case-control study reported on ERBB2 genetic variation. To our knowledge, this is also the 
Table 2

\begin{tabular}{|c|c|c|c|c|c|c|c|}
\hline SNP & Series & $\begin{array}{l}\text { Rare-allele } \\
\text { frequency }\end{array}$ & $\begin{array}{c}\text { Common homozygote } \\
\text { No. (\%) }\end{array}$ & $\begin{array}{c}\text { Heterozygote No. } \\
(\%)\end{array}$ & $\begin{array}{l}\text { Rare homozygote } \\
\text { No. }(\%)\end{array}$ & Number genotyped & $P(2 \mathrm{df})$ \\
\hline \multirow[t]{3}{*}{ SNP 1} & Cases & 0.13 & $1618(77)$ & $447(21)$ & $42(2)$ & 2107 & \\
\hline & Controls & 0.13 & $1645(75)$ & $511(23)$ & $33(2)$ & 2189 & 0.13 \\
\hline & OR $(95 \% \mathrm{Cl})$ & & 1 (ref) & $0.89(0.77-1.03)$ & $1.29(0.82-2.05)$ & & \\
\hline \multirow[t]{3}{*}{ SNP 2} & Cases & 0.25 & $1151(57)$ & $734(36)$ & $140(7)$ & 2025 & \\
\hline & Controls & 0.26 & $1219(55)$ & 839 (38) & $147(7)$ & 2205 & 0.48 \\
\hline & OR $(95 \% \mathrm{Cl})$ & & 1 (ref) & $0.93(0.82-1.05)$ & $1.01(0.79-1.29)$ & & \\
\hline \multirow[t]{3}{*}{ SNP 3} & Cases & 0.32 & $962(47)$ & $855(42)$ & $219(11)$ & 2036 & \\
\hline & Controls & 0.32 & $1022(46)$ & $956(43)$ & $230(11)$ & 2208 & 0.69 \\
\hline & OR $(95 \% \mathrm{Cl})$ & & 1 (ref) & $0.95(0.84-1.08)$ & $1.01(0.82-1.24)$ & & \\
\hline \multirow[t]{3}{*}{ SNP 4} & Cases & 0.25 & $1128(57)$ & $748(37)$ & $113(6)$ & 1989 & \\
\hline & Controls & 0.25 & $1230(57)$ & $791(37)$ & $134(6)$ & 2155 & 0.69 \\
\hline & OR $(95 \% \mathrm{Cl})$ & & 1 (ref) & $1.03(0.91-1.17)$ & $0.92(0.71-1.20)$ & & \\
\hline \multirow[t]{3}{*}{ SNP 5} & Cases & 0.33 & $911(45)$ & $870(43)$ & $233(12)$ & 2014 & \\
\hline & Controls & 0.33 & $960(44)$ & $983(45)$ & $238(11)$ & 2181 & 0.45 \\
\hline & OR $(95 \% \mathrm{Cl})$ & & 1 (ref) & $0.93(0.82-1.06)$ & $1.03(0.84-1.26)$ & & \\
\hline
\end{tabular}

OR, odds ratio; SNP, single-nucleotide polymorphism.

Table 3

\section{Estimated haplotype frequencies in cases and controls}

\begin{tabular}{llccc}
\hline Haplotype & Allele & Frequency (cases) & Frequency (controls) & $P^{b}$ \\
\hline$(1)$ & cctlA & 0.35 & 0.36 & 0.80 \\
$(2)$ & ctclP & 0.19 & 0.18 & 0.88 \\
$(3)$ & cctVA & 0.18 & 0.16 & 0.15 \\
$(4)$ & actlA & 0.13 & 0.13 & 0.49 \\
$(5)$ & ctcVP & 0.06 & 0.08 & 0.07 \\
$(6)$ & ccclP & 0.07 & 0.07 & 0.50 \\
$(7)$ & cctlP & 0.02 & 0.01 & 0.93
\end{tabular}

aPolymorphisms in 5' to $3^{\prime}$ order as indicated in Table 1. 'bGlobal score statistic $=6.91, \mathrm{df}=7, P=0.44$

first study on ERBB2 reporting results for more than two polymorphisms and looking for involvement of haplotypes in breast cancer predisposition. We performed a study of five common SNPs and found no evidence for association with breast cancer risk. Four of the polymorphisms may be functional: SNP 1 near the promoter region and SNP 2 in intron 1 could be involved in regulatory processes whereas SNP 4 and SNP 5 are nonsynonymous coding SNPs that could affect tyrosine kinase activity or protein structure [7]. Two association studies have previously reported a positive association between SNP 4 (1655V) and breast cancer risk $[8,14]$. Both genotyped about 700 individuals and showed a similarly increased risk for carriers of the Val allele $(\mathrm{OR}=$ over $90 \%$ power to detect a risk of this magnitude at the $10^{-4}$ level of significance. This suggests that previous positive findings may have been due to type I statistical errors. Neither could we replicate findings associating $1655 \mathrm{~V}$ with low-stage breast cancer or with breast cancer in younger women $[12,13]$. Positive results from stratified analyses should be treated with caution; very large sample sizes are required to obtain reliable results, the number of possible analyses that can be undertaken is large, and there is a strong possibility that one or more tests will be statistically significant simply by chance [24]. We could not carry out analyses within cases stratified by family history, because we only had incomplete family history data [15]. To investigate the possibility that a common polymorphism not 
included in our study might be involved in breast cancer predisposition, we constructed multilocus haplotypes and observed similar frequencies in cases and controls. We found six common haplotypes. Recently, the NIEHS Environmental Genome Project at the University of Washington released resequencing data based on 90 individuals (the PDR90 population; individual genotypes are available on line: http://egp.gs.washington.edu/genes.html) and identified nine common SNPs (frequency $\geq 5 \%$ ) in ERBB2. All the common haplotypes (frequency $\geq 5 \%$ ) were tagged by our set of five SNPs, even though, as expected given the multiethnicity of PDR90, differences in frequencies were seen between the two populations (data not shown). Crawford and colleagues resequenced 100 candidate genes involved in inflammation, lipid metabolism, and blood pressure regulation and showed that in a population of European descent the average number of common haplotypes per gene was 4.5, with a maximum number of 8 observed in only two genes [25]. We are therefore confident that we have detected all common ERBB2 haplotypes present in our population. We limited our study to common polymorphisms. A larger study set would be needed to identify a rarer polymorphism involved in disease predisposition. For example, dominant alleles with a frequency of $2 \%$ would require more than 4000 cases and 4000 controls to detect a relative risk of 1.5 significant at the $1 \%$ level with $90 \%$ power. We cannot exclude the possibility that a common SNP might have a differential effect in another ethnic group via gene-gene or gene-environment interactions, or that a predisposing SNP might be present exclusively in another population [26]. In summary, we conducted a large casecontrol study of $E R B B 2$ and breast cancer. We genotyped five common SNPs, including the much-studied $1655 \mathrm{~V}$ polymorphism, and saw no association with the disease. Our set of SNPs generated all common haplotypes, and no differences in haplotype frequencies were seen between cases and controls.

\section{Conclusion}

In our population, common ERBB2 polymorphisms are not involved in predisposition to breast cancer.

\section{Competing interests}

The author(s) declare that they have no competing interests.

\section{Authors' contributions}

PRB performed the experiments, carried out the analyses, and wrote the manuscript under the supervision of FL, PDP, and BAJP. CL and DMC managed the genotyping process. MS and NED supervised DNA samples collection. DFE was the statistical advisor and AMD was the laboratory manager. All authors read and approved the final manuscript.

\section{Acknowledgements}

Paula Smith contributed to the haplotype analysis. We thank the EPIC management team (K-T Thaw, S Oakes, S Bingham, R Luben, and J Russell) for access to control DNA. Patrick R Benusiglio is supported by the Ligue Genevoise contre le Cancer (N/Ref 0208). This work was funded by Cancer Research United Kingdom. BAJP is a Gibb Fellow of Cancer Research UK.

\section{References}

1. Familial breast cancer: collaborative reanalysis of individual data from 52 epidemiological studies including 58,209 women with breast cancer and 101,986 women without the disease. Lancet 2001, 358:1389-1399.

2. Pharoah PD, Antoniou A, Bobrow M, Zimmern RL, Easton DF, Ponder BA: Polygenic susceptibility to breast cancer and implications for prevention. Nat Genet 2002, 31:33-36.

3. Dite GS, Jenkins MA, Southey MC, Hocking JS, Giles GG, McCredie MR, Venter DJ, Hopper JL: Familial risks, early-onset breast cancer, and BRCA1 and BRCA2 germline mutations. J Natl Cancer Inst 2003, 95:448-457.

4. Prevalence and penetrance of BRCA1 and BRCA2 mutations in a population-based series of breast cancer cases. Anglian Breast Cancer Study Group. Br J Cancer 2000, 83:1301-1308.

5. Yarden $\mathrm{Y}$, Sliwkowski MX: Untangling the ErbB signalling network. Nat Rev Mol Cell Biol 2001, 2:127-137.

6. Menard S, Pupa SM, Campiglio M, Tagliabue E: Biologic and therapeutic role of HER2 in cancer. Oncogene 2003, 22:6570-6578.

7. Fleishman SJ, Schlessinger J, Ben Tal N: A putative molecularactivation switch in the transmembrane domain of erbB2. Proc Natl Acad Sci USA 2002, 99:15937-15940.

8. Xie D, Shu XO, Deng Z, Wen WQ, Creek KE, Dai Q, Gao YT, Jin F, Zheng W: Population-based, case-control study of HER2 genetic polymorphism and breast cancer risk. J Natl Cancer Inst 2000, 92:412-417.

9. Baxter SW, Campbell IG: Re: Population-based, case-control study of HER2 genetic polymorphism and breast cancer risk. $J$ Natl Cancer Inst 2001, 93:557-559.

10. Hishida A, Hamajima N, Iwata H, Matsuo K, Hirose K, Emi N, Tajima $\mathrm{K}$ : Re: Population-based, case-control study of HER2 genetic polymorphism and breast cancer risk [letter]. $J$ Nat/ Cancer Inst 2002, 94:1807-1808.

11. Keshava C, McCanlies EC, Keshava N, Wolff MS, Weston A: Distribution of HER2(V655) genotypes in breast cancer cases and controls in the United States. Cancer Lett 2001, 173:37-41.

12. McKean-Cowdin R, Kolonel LN, Press MF, Pike MC, Henderson BE: Germ-line HER-2 variant and breast cancer risk by stage of disease. Cancer Res 2001, 61:8393-8394.

13. Millikan R, Eaton A, Worley K, Biscocho L, Hodgson E, Huang WY, Geradts J, lacocca M, Cowan D, Conway K, et al.: HER2 codon $\mathbf{6 5 5}$ polymorphism and risk of breast cancer in African Americans and whites. Breast Cancer Res Treat 2003, 79:355-364.

14. Montgomery KG, Gertig DM, Baxter SW, Milne RL, Dite GS, McCredie MR, Giles GG, Southey MC, Hopper JL, Campbell IG: The HER2 1655V Polymorphism and Risk of Breast Cancer in Women < Age 40 Years. Cancer Epidemiol Biomarkers Prev 2003, 12:1109-1111.

15. Wang-Gohrke S, Chang-Claude J: Re: Population-based, casecontrol study of HER2 genetic polymorphism and breast cancer risk. J Natl Cancer Inst 2001, 93:1657-1659.

16. Gabriel SB, Schaffner SF, Nguyen H, Moore JM, Roy J, Blumenstiel B, Higgins J, DeFelice M, Lochner A, Faggart M, et al.: The structure of haplotype blocks in the human genome. Science 2002, 296:2225-2229

17. Carlson CS, Eberle MA, Rieder MJ, Yi Q, Kruglyak L, Nickerson DA: Selecting a maximally informative set of single-nucleotide polymorphisms for association analyses using linkage disequilibrium. Am J Hum Genet 2004, 74:106-120.

18. Haiman CA, Stram DO, Pike MC, Kolonel LN, Burtt NP, Altshuler D, Hirschhorn J, Henderson BE: A comprehensive haplotype analysis of CYP19 and breast cancer risk: the multiethnic cohort. Hum Mol Genet 2003, 12:2679-2692.

19. Day N, Oakes S, Luben R, Khaw KT, Bingham S, Welch A, Wareham N: EPIC-Norfolk: study design and characteristics of the 
cohort. European Prospective Investigation of Cancer. $\mathrm{Br} \mathrm{J}$ Cancer 1999, 80(Suppl 1):95-103.

20. Chen Y, Gill GN: Positive and negative regulatory elements in the human erbB-2 gene promoter. Oncogene 1994, 9:2269-2276.

21. Armitage $P$, Berry G: The size of a statistical investigation. In Statistical Methods in Medical Research Oxford: Blackwell Scientific Publications; 1994:195-206.

22. Ding K, Zhou K, He F, Shen Y: LDA - a java-based linkage disequilibrium analyzer. Bioinformatics 2003, 19:2147-2148.

23. Schaid DJ, Rowland CM, Tines DE, Jacobson RM, Poland GA: Score tests for association between traits and haplotypes when linkage phase is ambiguous. Am J Hum Genet 2002, 70:425-434.

24. Colhoun HM, McKeigue PM, Davey SG: Problems of reporting genetic associations with complex outcomes. Lancet 2003, 361:865-872.

25. Crawford DC, Carlson CS, Rieder MJ, Carrington DP, Yi Q, Smith JD, Eberle MA, Kruglyak L, Nickerson DA: Haplotype diversity across 100 candidate genes for inflammation, lipid metabolism, and blood pressure regulation in two populations. $\mathrm{Am} \mathrm{J}$ Hum Genet 2004, 74:610-622.

26. Cui J, Zhou X, Chazaro I, DeStefano AL, Manolis AJ, Baldwin CT, Gavras $\mathrm{H}$ : Association of polymorphisms in the promoter region of the PNMT gene with essential hypertension in African Americans but not in whites. Am J Hypertens 2003, 16:859-863. 